NASA Technical Memorandum 100407

\title{
Preliminary Flight Assessment of the X-29A Advanced Technology Demonstrator
}

John W. Hicks and Neil W. Matheny

(UASA-TA-100407) PRELIAIMAEY RLIGBT ISSESSAEHT OR THE I-29A IDVAHCBD TBCBHOLOGY DEgonstratog (MASA) $15 \mathrm{p}$ avail: urIs hC 102/ar 101 CSCL 01C
ע87-26906

Onclas 0093402 
NASA Technical Memorandum 100407

\section{Preliminary Flight Assessment of the X-29A Advanced Technology Demonstrator}

John W. Hicks and Neil W. Matheny

Ames Research Center, Dryden Flight Research Facility, Edwards, California

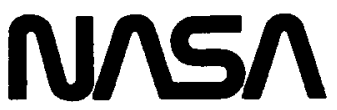

National Aeronautics and

Space Administration

Ames Research Center

Dryden Flight Research Facility

Edwards, California 93523-5000 


\author{
John W. Hicks* and Neil W. Matheny ${ }^{\star \star}$ \\ NASA Ames Research Center \\ Dryden Flight Research Facility \\ Edwards, Cal ifornia
}

\section{Abstract}

Several new technologies integrated on the $x-29 A$ advanced technology demonstrator are being evaluated for the next generation of fighter aircraft. Some of the most noteworthy ones are the forward-swept wing, digital fly-by-wire flight control system, close-coupled wing-canard configuration, aeroelastically tailored composite wing skins, three-surface pitch control configuration, and a highly unstable airframe. The expansion of the aircraft $1-g$ and maneuver flight envelopes was recently completed over a two-year period in 84 flights. Overall flight results confirmed the viability of the aircraft design, and good agreement with preflight predictions was obtained. The individual technologies' operational workability, and performance were confirmed. This paper deals with the flight test results and the preliminary evaluation of the $X-29 A$ design and technologies. A summary of the primary technical findings in structural static loads, structural dynamic characteristics, flight control system characteristics, aerodynamic stability and control, and aerodynamic performance is presented.

\section{Nomencl ature}

ACC automatic camber control

AR analog reversion

ASW aft-swept wing

BFF body freedom flutter

$C_{D}$ coefficient of drag

r.L coefficient of $\mathrm{lift}$

DR digital reversion

FCS flight control system

FDMS flight deflection measurement system

FM frequency modulation

FSW forward-swept wing

LED light-emitting diode

MCC manual camber control

ND normal digital

$\mathrm{N}_{2}$ normal acceleration

PA power approach

\footnotetext{
*Aerospace Engineer. AlAa Member.
} * Chief Engineer, X-29A Program.
PCM pulse-code modulation

UA up and away

\section{Introduction}

The $X-29 A$ advanced technology demonstrator was used to evaluate a number of integrated advanced fighter technologies for the next generation of aircraft. The initial flight test program objective was to expand the aircraft $1-g$ and maneuver flight envelopes prior to more detailed research evaluation of the various technologies. This initial phase yielded preliminary evaluation of these technology concepts. This paper describes the aircraft and the technology concepts. It also gives a summary of the flight test results and the major findings to date in several technical disciplines including structural loads, structural dynamics, flight control system, aerodynamic stability and control, aircraft performance, external airframe pressure surveys, and aerodynamic buffet characteristics.

The $X-29 A$ project was begun by the Defense Advanced Research Projects Agency (DARPA) in 1977. The aircraft was designed and built by the Grumman Aerospace Corporation and shipped to the Dryden Flight Research Facility of the NASA Ames Research Center (Ames-Dryden) in October 1984 to begin the two-year flight envelope expansion and concept evaluation phase. Ames-Dryden was the responsible test organization for flight operations, safety of flight, range operations, project planning, and overall conduct of the filight test program. Other participants on the $X-29 \mathrm{~A}$ flight test team included Grumman, the Air Force Wright Aeronautical Laboratories Advanced Development Projects office (ADPO), and the U.S. Air Force Flight Test Center.

The first flight was on December 14, 1984, and the 84th flight, ending the envelope expansion phase, was completed on November 14, 1986. A total of 104 flights were completed by the end of 1986; the last 20 flights obtained data in handling qualities, systems testing, and structures to begin the follow-on flight research phase.

The prime objective of the initial flight test program was accomplished with the clearing of the $1-g$ flight envelope to the maximum Mach number at several altitudes up to $50,000 \mathrm{ft}$. Additionally, the aircraft maneuver envelope was expanded in angle of attack up to $20^{\circ}$ and in normal load factor up to $5.7 \mathrm{~g}$. The primary areas of technical interest included the predicted induced drag reduction of the forward-swept wing (FSW), demonstration of the structural divergence-free envelope of the FSW, aeroservoelastic characteristics, and the performance of the digital flyby wire flight control system (FCS) on a highly unstable airframe. Other areas included the overall flying qualities of a three-surface pitch 
control configuration, aerodynamic parameter identification on a highly unstable airplane, aerodynamic buffet characteristics for the close-coupled canard and FSW configuration, and the overall static loads distributions.

\section{Aircraft Description and Technology Advantages}

The $x-29 A$ advanced technology demonstrator (Fig. 1) is a single-seat, fighter-type aircraft incorporating several new technology concepts that synergistically work for aircraft performance improvements. The most notable feature is the FSW with a $29.3^{\circ}$ leading edge sweep and a 5 percent thin supercritical airfoil section. The upper and lower surface wing skins are made of a graphiteepoxy composite material and are used to aeroelastically tailor the wing deflection and inhibit wing structural divergence. The wing has no leading edge devices, but incorporates full-span trailing edge, dual-hinged flaperons that are divided into three segments on each wing. The midwing and outboard segments are driven by a single hydraulic actuator, housed in a fairing under the wing. The inboard segment is driven by a separate actuator, located near the wing root. The two wing camber control modes are the automatic camber control (ACC) set by the flight control system as a function of flight condition and the manual camber control (MCC) set in discrete intervals by the pilot. In the ACC mode, the flaperons vary the camber of the wing to increase derodynamic efficiency over the flight envelope. The MCC mode was used only as a flight test mode. Full flaperon travel was from $10^{\circ}$ trailing edge up to $24.75^{\circ}$ trailing edge down. Maximum $\mathrm{flaperon}$ rate was $68 \mathrm{deg} / \mathrm{sec}$.

Another feature of the aircraft is its active three-surface pitch control configuration. In addition to the wing flaperons, this includes the canards and the aft-mounted strake flaps. Symmetric deflection of these surfaces is controlled by the FCS to provide trim and pitch control. The canard area is equal to 20 percent of the wing area. The canards act as a powerful lift and pitch generator. They are of single-piece construction with a deflection range of $30^{\circ}$ leading edge up to $60^{\circ}$ leading edge down and move at rates of up to $100 \mathrm{deg} / \mathrm{sec}$. The strake flaps travel from $30^{\circ}$ tratling edge up to $30^{\circ}$ trailing edge down. Differential deflection of the flaperons provides the sole source of roll control. Yaw control is provided by a single-piece rudder mounted on a fixed vertical stabilizer.

The presence of the canards results in an otherwise neutrally stable airframe having a negative static margin of nominally 35 percent. This high degree of instability necessitates high levels of stability augmentation, provided by the triplex digital fly-by-wire FCS operating at an update rate of $40 \mathrm{~Hz}$. The FCS consists of three flight modes: the prime normal digital (ND) mode, the digital reversion (DR) mode, and the analog reversion (AR) mode. Each FCS mode has both an aircraft cruise mode, known as "up and away" (UA), and the power approach (PA) mode. Extensive gain scheduling is employed in each FCS mode except in the DR and AR power approach configuration. A more detailed description of this system can be found in Ref. 1.
The aircraft is powered by a single 16,000-1bclass General Electric F $404-G E-400$ afterburning engine. The engine is mounted in the fuselage with two side-mounted, fixed-geometry inlets that were optimized for transonic performance. Maximum aircraft takeoff gross weight is 17,800 ib with a 4,000-1b fuel capacity in two fuselage and two strake tanks.

\section{Flight Test Instrumentation System}

All 691 measured data parameters were telemetered to the ground for recording, real-time analysis, and control room monitoring. The aircraft did not have an onboard recording capability. The 10-bit remote unit pulse-code modulation (PCM) system sampled data from 25 to 400 samples/sec, depending on the desired frequency range to be covered. The digital data were processed by five PCM units, and an interleaver device merged the data stream along with the output from the flight control computers' ARINC 429 (Aeronautical Radio, Inc.) bus. The data were downl inked as a serial PCM stream. A constant-bandwidth frequency modulation (FM) system was installed to process highresponse acceleration and vibration data. This FM signal was merged with the rest of the digital data from the interleaver and downlinked along with the pilot's voice signals. The data parameter set included measurements for structural loads, structural dynamics, flight controls, stability and control, aircraft subsystems, propulsion and performance, wing deflections, buffet, and external pressure distributions. A schematic of the instrumentation system is shown in Fig. 2 .

\section{Special Test Equipment}

Aircraft instrumentation included a pitotstatic noseboom with angle-of-attack and sideslip angle vanes. The left side of the aircraft had 176 flush-mounted static pressure orifices, located in two rows on the canard, four rows on the wing, and one row along the strake and strake flap to measure pressure distribution.

Twelve infrared light-emitting diodes (LEDS) were mounted on the top of the right wing, and a dual receiver was mounted in the right side of the fuselage above the wing root as part of the flight deflection measurement system (FDMS), which meas ures wing deflection and twist in flight.

Finally, the underside of each wing contained an aerodynamic fairing with a flight test eccentric rotary-mass flaperon structural excitation system and mid- and outboard flaperon hydraulic actuator. The structural excitation system was used to excite the flap-tab structural modes to provide aeroservoelastic clearance of that structure during the envelope expansion. Figure 3 shows the layout of these configurations.

\section{Technology Concepts}

The key objectives in developing the technologies that are incorporated into the $x-29 A$ design included establishing new airframe design freedoms and options. This manifested itself in such things as a reduction in aircraft size and gross weight with the FSW concept, dependent on mission, while simultaneously increasing volu- 
metric efficiency around the aircraft center of gravity. The FSW is predicted to exhibit better lateral control at higher angles of attack, compared with an aft-swept wing (ASW), because of the inboard flow of air over the top of the wing, which inhibits wingtip stall and thus loss of aileron effectiveness as angle of attack increases. The technology of using advanced composites, coupled with aeroelastic tailoring of those composites in the wing skins, allows the FSW to have enough structural stiffness to resist its natural tendency toward structural divergence.

Another objective was to demonstrate that adequate levels of dynamic stability can be achieved by controlling an unstable airframe with a closecoupled canard, symmetric flap, and strake-flap combination. The highly relaxed longitudinal static stability has the potential advantage of increasing transonic and high-angle-of-attackmaneuverability, while reducing trim drag changes with changing flight conditions, and enhancing overall aerodynamic efficiency. The close-coupled wing-canard configuration allows for a better elliptical lift distribution than with the current wing configuration alone and improves aircraft maneuverability by contributing a positive lift component to the wing lift, in contrast to an aft-mounted horizontal tail, which can produce a negative 1 ift component.

Another technology objective was to evaluate potential drag reduction concepts with the FSW, the supercritical-wing airfoil, and the ACC wing camber control mode to enhance transonic and offdesign performance. The FSW was predicted to save up to 13 percent in aircraft drag transonically because of a substantial reduction in wing profile drag in comparison to an ASW of the same aspect ratio, taper ratio, wing area, and shock location and sweep. This is primarily because the FSW requires less leading edge sweep for the same shock sweep and location. The corresponding greater sweep of the FSW trailing edge in turn results in a greater shock sweep angle, which reduces the shock strength, reducing the wave drag and the drag caused by shock-induced flow separation. The geometrical differences between the FSW and ASW with the same shock sweep angle results in a more inboard location of the wing center of pressure on the FSW, yielding a lower bending moment for the FSW of the same aspect ratio and taper ratio. This lowers the wing box bending load and structural weight at a given aspect ratio in comparison to an equivalent ASW or, alternately, allows an increase in the aspect ratio for the same bending load. The allowable increase in aspect ratio has an additional advantage of increasing aerodynamic efficiency and reducing the induced drag of the wing. More discussions of the X-29 technologies can be found in Ref. 2 .

\section{General Discussion of Results}

The primary objective of this initial flight test phase was to expand the flight and maneuvering envelopes of the aircraft. A great deal was learned about the workability of the technology concepts in the process of flying the aircraft and expanding the flight envelope. A large volume of data was gathered over the 104 flights that averaged some 65 test maneuvers per flight. These data were analyzed and evaluated not only to clear the aircraft to the next step of its flight envelope, but to give a preliminary evaluation of the viability of the incorporated technologies. Additional flight research work awaits the fully cleared flight envelope, dedicated disciplinary flights with custom-tailored test maneuvers, instrumentation system improvements, or a combination of these.

The flight envelope expansion phase was successfully completed, without significant incident or problems. The aircraft, in general, proved itself to be a reliable flying technology test bed and flew in a relatively conventional manner. The following sections of this paper will highlight and summarize the major findings of this initial flight test evaluation of the $X-29 A$. Specific discussions by technical discipline summarize the most noteworthy and interesting findings from the envelope expansion phase. A complete description of the flight test techniques used to generate all the engineering disciplines data can be found in Ref. 3 .

\section{Structural Dynamics}

Structural dynamics includes monitoring the stability of the airframe elastic modes (aeroelasticity) and the stability of the interaction of the elastic modes with the flight control system (aeroservoelasticity). Frequency and damping trends for 12 structural modes of the aircraft were established in all three FCS modes to provide stability trend data over the entire flight envelope. The five modes of primary concern were monitored in real time and included the symetric and antisymmetric wing first bending modes, the fuselage vertical and lateral first bending modes, and the vertical fin first bending mode. Flight maneuvers used to generate the data included a 1 -min stabilized point at a given Mach number and altitude, utilizing natural turbulence to excite the airframe structure, followed by control surface raps. Typical modal frequency and damping results can be seen in Fig. 4. In general, the measured frequency and damping levels agreed well with closed-10op aeroservoelastic predictions and were satisfactory, with no adverse trends. Pilot stick raps and natural turbulence excitation of the airframe yielded sufficient quality flight data.

A flaperon eccentric rotary-mass excitation system used a frequency-sweep vibration input in an attempt to excite a predicted supersonic midflaperon torsion flutter mode. The shaker system excited the predicted flutter mode, but the response bandwidth was too wide for the identification of structural frequency and damping.

A dynamic interaction, known as body-freedom flutter (BFF), was predicted to occur when the wing first bending mode frequency reduced and coupled with the aircraft longitudinal short period mode. The BFF mechanism was predicted to act as a precursor as a function of dynamic pressure to the static wing divergence and was therefore carefully monitored during envelope expansion. At low Mach numbers, the wing first bending mode frequency was just above predictions and remained there as the envelope expansion con- 
tinued to maximum Mach number and maximum dynamic pressure. This indicated that the predicted BFF airspeed was outside of the $1-g$ flight envelope.

\section{Structural Loads}

The airframe was subjected to an $8-g$ proof test loading (design limit) and was restricted in flight to 80 percent of that load factor. This resulted in flight normal acceleration limits of $6.4 \mathrm{~g}$ at subsonic Mach numbers and $5.2 \mathrm{~g}$ at supersonic Mach numbers. Full flight loads expansion was not completed in this phase, but a maximum load condition of $5.7 \mathrm{~g}$ was demonstrated. Most ineasured airframe loads were in good general agreement with predictions, with the exception of the canard torsion loads. A time history of the canard torsion loads experienced during a windup turn at Mach 0.95 and an altitude of $10,000 \mathrm{ft}$ is shown in Fig. 5. Also shown are the predicted loads based on unit load predictions using the actual flight test conditions as inputs. Canard torsion loads were shown to be consistently higher than predicted at transonic Mach numbers, especlally at the high dynamic pressure conditions. Canard torsion loads were also found to be highly sensitive to aircraft sideslip angle. The difference between the flight test data and the predictions is not fully understood at this time and is still under investigation.

\section{Structural Divergence}

A challenging envelope expansion problem for the $X-294$ was the monitoring of the wing static divergence characteristics of the FSW. This phenomenon was tracked closely and analyzed conservatively because this was the first time that this type of clearance had been performed in flight test at the conditions flown by the $X-294$. Data were generated from constant altitude windup turn and pushover-pullup maneuvers. Both strain gage loads data and twist measurements from the FDMS were used to estimate the divergence airspeeds using the Southwell technique. Although this was the first application of the Southwell technique to flight test data, it had been used previously to analyze wind tunnel data. Further details of the analysis technique can be found in Ref. 4 . The divergence airspeed estimated from the Southwell analysis was shown to be sensitive to a number of factors including measurement uncertainties, maneuver technique, aerodynamic phenomena, and strain gage loads measurement stations. Preliminary results indicate a lower divergence speed than predicted, but the divergence airspeed was still outside the flight envelope. Flight results to date confirm the feasibility of designing an FSW-configured aircraft that inhibits the natural tendency toward static wing divergence by using strong, lightweight layups of graphite-epoxy composites for the wing covers.

\section{Aerodynamic Performance}

The primary aerodynamic performance research objective was to determine the induced drag polar levels or the drag polar shape above the minimum parasite drag level, where the FSW was predicted to lower induced drag levels. Polar shape data could only be obtained in the subsonic portion of the flight envelope during the flight envelope expansion phase since a lack of afterburner fuel flow instrumentation prevented the calculation of an accurate afterburner thrust in supersonic flight. Other difficulties arose in the angleof-attack calibration and large maneuver dynamics effects from being off the optimum wing ACC camber schedule. Details of the challenges in modeling the $X-29 A$ subsonic drag polar can be found in Ref. 5. Dynamic test techniques used to obtain the drag data included constant thrust windup turns and pushover-pullup maneuvers.

Typical subsonic to low transonic dray polar results can be seen in Fig. 6 . The basic drag polar shapes met or exceeded wind-tunnel-based predictions. Dynamic effects associated with nonoptimum ACC settings caused some performance penalty in attainable lift at a given drag level. The wing ACC schedule was designed to optimize 1 ift-to-drag ratio only during steady-state flight, such as the 1-g trimmed condition, and not during highly dynamic aircraft maneuvers. A thrust-calibrated engine will be used for the follow-on flight research performance phase to obtain more precisely measured airframe drag levels and polar shapes.

\section{Aerodynamic Pressure Distribution Survey}

A pressure survey was made of the left canard, wing, and strake area and compared with wind tunnel results over a range of flight conditions. The instrumented full-scale canard surface had two rows of pressure instrumentation; however, the wind tunnel model had only the inside row of static pressure orifices on the canard. Data were obtained from $1-g$ stabilized flight, windup turns and pushover-pullups. As with other discipline areas, the wing pressure flight-to-prediction correlation was impacted by the angle-of-attack uncertainties because the predicted pressure distributions were based on measured angle of attack.

In general, flight results agreed well with predictions; a typical example is shown in Fig. 7 . The pressure distributions are typical of a supercritical airfoil and correlate well with the wind tunnel data on both the top and bottom of the wing. Wingspan loads, derived from the pressure measurements, also agreed closely with predictions, except on the most inboard body strake position. These differences are attributed to the differences between the aircraft and wind tunnel model aft-end configurations. Wing shock locations were derived from the pressure rise and generally matched predictions.

\section{Flight Control System}

The FCS was monitored closely in flight to insure that aircraft dynamic stability levels were maintained throughout the flight envelope. Actual aircraft phase and gain margins (Fig. 8) were computed in near real time to support envelope expansion using frequency response analysis techniques. The FCS generally performed according to predictions and maintained phase and gain margins above the minimums, except at low-altitude transonic conditions, as described below. In most cases. differences between actual and predicted response characteristics could be attributed to differences 
between the full-scale aerodynamics and wind tunnel predictions. Using the onl ine frequency response analysis techniques, a loss in phase and gain margins was detected as the envelope was being cleared below $20,000 \mathrm{ft}$ altitude at transonic Mach numbers. Loop gains in the pitch axis control laws were modified, allowing the envelope expansion to be successfully completed. Figure 9 shows the phase and gain margins at $15,000 \mathrm{ft}$ altitude as functions of Mach number and the effects of the loop gain change.

The $x-29 A$ program utilized a collocated, hardware-in-the-loop-type simulation to effect a safe and efficient envelope expansion. This capability is considered necessary for vehicles of this complexity.

The $X-29 A$ has demonstrated the successful flight test of an active three-surface longitudinal control vehicle with an FCS that utilizes inner-loop stabilization and outer-loop performance optimization. There have been no unintended flight control system mode changes and only four minor hardware failures, of which only one occurred in flight. The one in-flight failure affected one of six roll rate gyros and was eventually detected by the onboard FCS system.

\section{Handling Qualities}

The basic handling qualities proved adequate for the open-loop piloted tasks required during flight envelope expansion. Some flying qualities maneuvers were flown to obtain initial handing qualities assessments. Figure 10 shows a summary of the pilot ratings (Cooper-Harper system) for several formation flying and tracking tasks. This figure shows that the $X-29 A$ generally has level II handling qualities. The primary flying qualities concern was described as a lack of control stick harmony because the longitudinal stick displacements are large compared with the lateral stick displacements.

The airplane has a slight, but not objectionable, tendency to overrotate at nose wheel $1 \mathrm{ift}$ off. The pilot has to push the stick forward to execute the landing because of the attitude hold nature of the FCS. The $X-29 A$ normal acceleration response to turbulence at the pilot station was lower than that of the T-38 chase aircraft. This was determined by the pilots' qualitative comparisons of the response of the $x-29 A$ and the chase aircraft flying side-by-side. The individual contributions of the aircraft configuration and flight control system to this characteristic are not known at this time.

\section{Aerodynamic Stability and Control}

Since the wing flaps are used as the primary trimming surface on the $X-29 A$, the position of the wing flaps during maneuvering flight is dependent upon the rate of the maneuver. Aircraft steadystate trim is accomplished by positioning the wing flaps to maintain the canard at a position determined from a reference canard position schedule that is a function of Mach number, altitude, and angle of attack. This schedule was predicted to provide minimum drag over the flight envelope for steady-state conditions. The error signal between the actual canard position and this reference schedule is integrated in the FCS software and used to drive the wing flaps to minimize the error. The rate of movement of the flaps in this trim mode is 1 imited by the FCS to $2 \mathrm{deg} / \mathrm{sec}$ to minimize the destabilizing effect of this mode on the longitudinal short-period dynamics. This relatively slow rate of travel in the trim mode prevents the flaps from achieving the optimum position in rapid maneuvering and therefore causes the configuration of the airplane to be dependent upon the history of maneuvering, as shown in Fig. 11 . This figure shows the flap position for two windup turns performed at similar flight conditions and the predicted steady-state flap position as functions of angle of attack. The flap position during the slow windup turn approximates the predicted position, while the flap position for the rapid windup turn is significantly more trailingedge-up (more negative). Thus the airplane wing flap position during a slow windup turn is significantly different from that during a rapid one.

The lateral-directional maneuvering characteristics are typical of fighter-type aircraft, with the exception of an FCS limit on maximum roll rate and the effects of a relatively low value of dihedral effect. The maximum roll rate was conservatively limited to reduce the possibility of coupling with the highly unstable pitch axis. The $x-29 A$ has a relatively low value of rolling moment due to sideslip (dihedral effect). In many circumstances, the rolling moment due to rudder is higher than the rolling moment due to sideslip and results in a negative slope of aileron position with sideslip. However, this characteristic is masked to the pilot by the control system, with the exception of the power approach configuration where the airplane has an apparent negative dihedral effect. This effect was slight and did not materially influence wind limits for crosswind landings.

Fl fght-determined lateral-directional parameter estimates are generally near predictions. The most significant difference is in the yawing moment due to aileron parameter. This parameter is approximately double the predicted value at high subsonic speeds and then transitions to near predictions at supersonic speeds. As the flight envelope was being expanded, this parameter was extrapolated into the supersonic flight region, based on the subsonic estimates. The yawing characteristics during a roll maneuver at supersonic speeds were predicted to couple with the longitudinal axis and cause a pitch transient in excess of $3 \mathrm{~g}$, which would have exceeded the temporary $3-g$ supersonic flight load limit. However, the reduced flight test value of yawing moment due to aileron at the supersonic speeds resulted in maximum supersonic pitch transients of only $1.5 \mathrm{~g}$ (Fig. 12).

Attempts to estimate longitudinal parameters were greatly affected by the high level of control augmentation and the highly unstable aircraft model. An interactive parameter identification program 6 was used for this analysis and is considered crucial to the successful accomplishment of the longitudinal parameter identification. This program allowed the operator to observe the 
progress of the estimation and to modify the procedure when warranted.

The dirplane is heavily damped in the longitudinal axis, making it impossible to obtain any oscillatory motion that is not driven by the controls. The output error minimization method for parameter identification was difficult to use with the highly unstable model because small variations in any of the parameters caused the output errors to be very large due to the instability, compared to small improvements in the match of the dynamic content of the maneuver. These difficulties were overcome by using a pitch doublet maneuver that had both a fast doublet to help define the control derivatives and a slow doublet that defined the angle-of-attack derivatives, and by using an interactive parameter identification program. The pitch damping derivative could not be determined. Because the three control surfaces move in unison, resulting in highly correlated control surface position measurement data, their individual effects could not be determined. A value of the canard derivative was estimated that includes any errors in the prediction of all three surfaces. The flight test results show that the vehicle is generally more stable (less unstable) than predicted and that the total pitch control effec$t$ iveness is lower than predicted at Mach numbers below 0.9 and higher than predicted for Mach numbers greater than 0.95 , as shown in Fig. 13 . These two effects made necessary the modification of control system gains at high dynamic pressures, as mentioned previously.

\section{Buffet Characteristics}

Buffet characteristics were determined by andlysis of the dynamic component of wingtipand canard-tip-mounted accelerometers. Flight test data show that with the current control system reference canard schedule, which tends to maintain the canard at low deflections for performance optimization, the canard encounters flow separation at lower angles of attack than the wing throughout the subsonic flight region. The upwash of the wing on the canard combined with the nearzero canard deflection at these conditions is primary cause of early canard flow separation. Measured wing and canard buffet intensities are considered moderate to high, but the pilots reported only mild buffet levels, due to the high frequencies of the buffet response at the cockpit. This results in the pilot sensing it more like a buzz than a buffet. The buffet intensity rise for the wing of the $X-29 A$ occurs at significantly higher normal force coefficients (Fig. 14), compared with those of other contemporary fighter-type aircraft, such as the $Y F-17$ and the $F-15$. It should be noted that normal force coefficient is based upon the reference wing area which, for the $x-29 A$, is the trapezoidal outer wing panel extended into the aircraft center line and does not include the canard surface area. Like most other aircraft, the $x-29 A$ encounters a moderate wing rock at angles of attack slightly above that for buffet intensity rise and exhibits heavy wing rock at the highest angle-of-attack conditions tested.

\section{Conclusions}

The $X-29 A$ incorporated several new technologies and has flown these in combination with several other advanced technologies. The airplane has been highly reliable and has encountered only minor discrepancies in its predicted characteristics and operational capability. Structural dynamics characteristics were near predictions throughout the flight envelope and indicated that the body freedom fiutter airspeed was outside the flight envelope. The static loads characteristics were generally near predictions, with the exception of the transonic canard loads at high dynamic pressures where higher than predicted torsion loads were found. Flight test estimation of the wing divergence airspeed using the Southwell technique was highly sensitive to errors in measurement parameters. The limited aerodynamic performance data shows that the airplane met or exceeded predictions at subsonic and transonic Mach numbers. The flight control system has worked well, providing adequate handling qualities. The longitudinal aerodynamic stability and control characteristics are unusual and difficult to estimate from flight data. The buffet characteristics show that the airplane has a higher wing buffet intensity rise boundary than most contemporary fightertype aircraft.

The $x-29 A$ is an excellent technology demonstrator. The airplane and its related systems have performed well. The airplane is now in a flight research phase which will provide more detailed data for understanding the contributions of the individual technologies.

\section{References}

1 Gera, Joseph, "Dynamics and Controls Flight Testing of the X-29A Airplane," NASATM-86803, 1986.

2spacht, G., "The Forward Swept Wing: A Unique Design Challenge," AIAA-80-1885, Aug. 1980.

3Hicks, John. W., Cooper, James M. Jr., and Sefic, Walter J., "Flight Test Techniques for the X-29A Aircraft," AIAA-87-0082, Jan. 1987.

${ }^{4}$ Ricketts, Rodney $H_{.}$, and Doggett, Robert V., Jr., "Wind-Tunnel Experiments on Divergence of Forward-Swept Wings," NASA TP-1685, 1980.

5Hicks, John W., Kania, Jan, Pearce, Robert, and Mills, Glen, "Challenges in Modeling the $X-29 A$ Flight Test Performance," AIAA-87-0081, Jan. 1987.

6Maine, Richard E., Murray, James E., "Application of Parameter Estimation to Highly Unstable Aircraft," NASA TM-88266, 1986. 

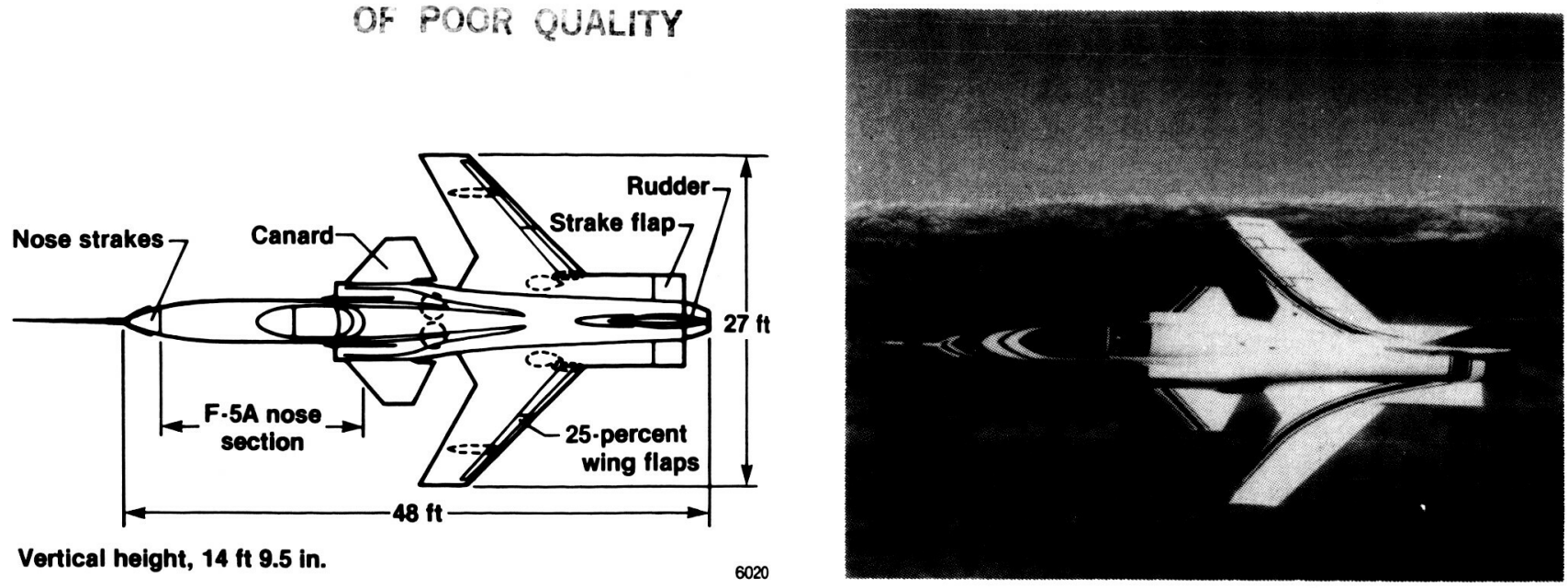

Vertical height, 14 ft 9.5 in.

Fig. 1 X-29A advanced technology demonstrator.

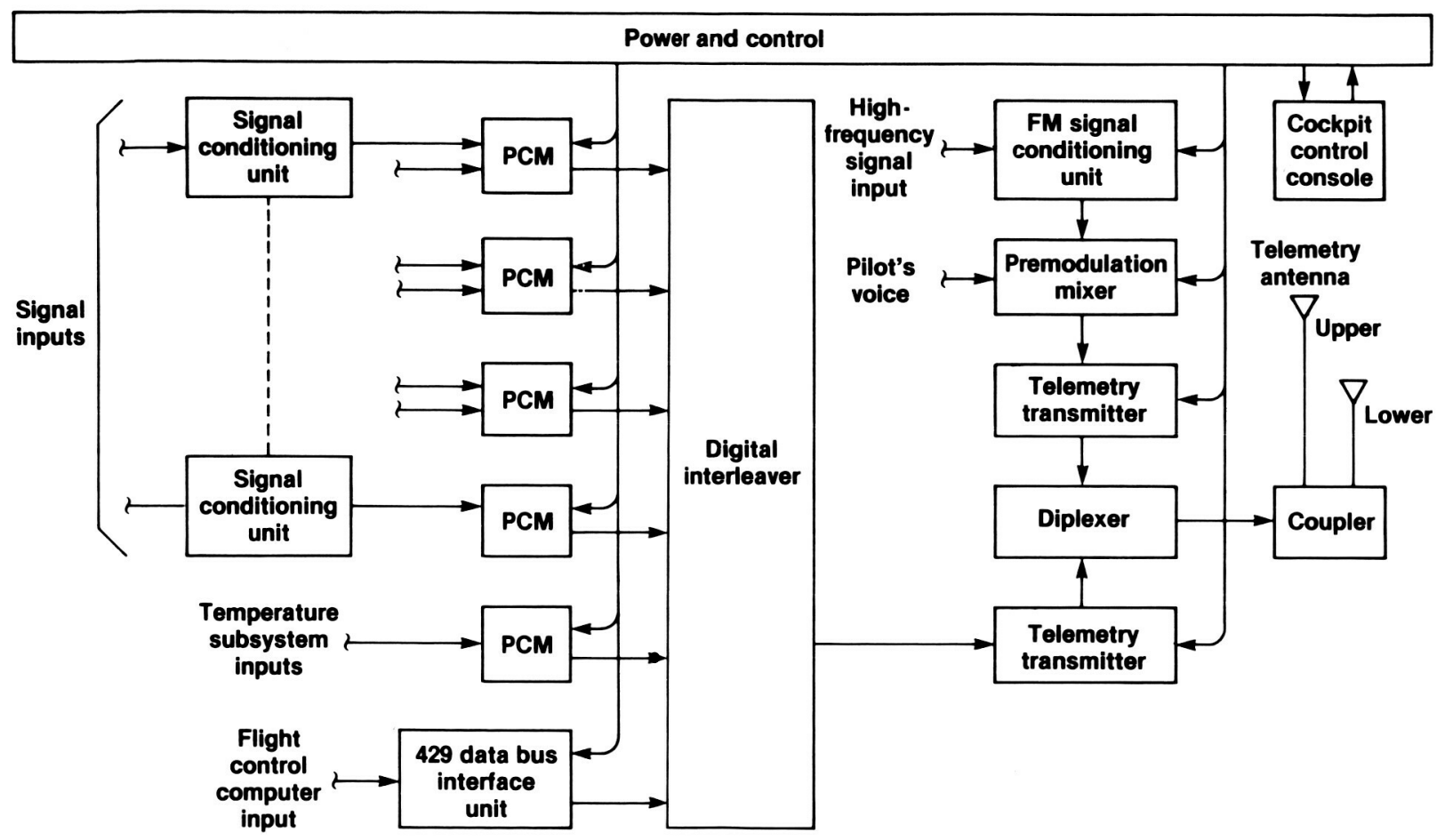

Fig. 2 X-29A data acquisition system. 


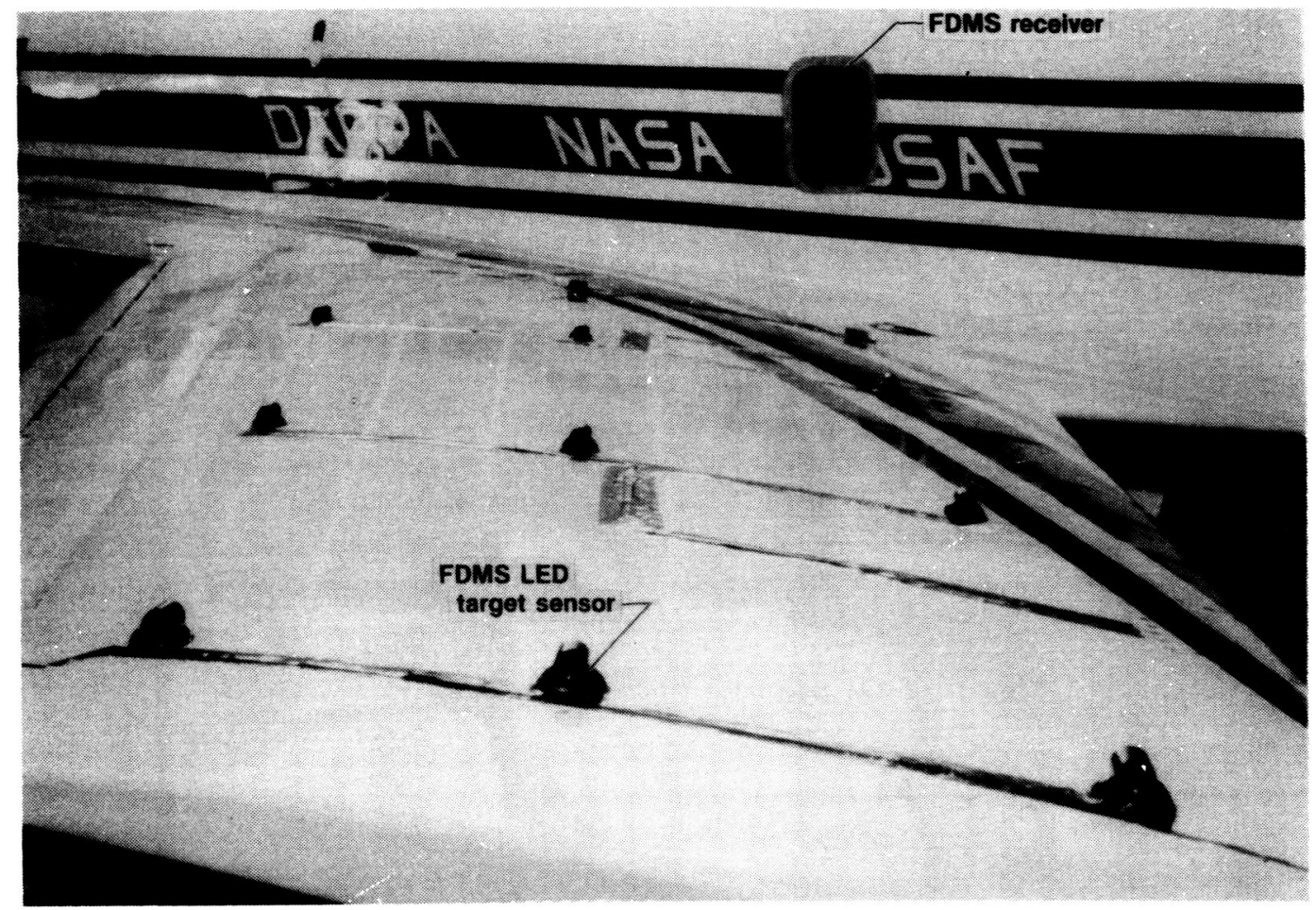

(a) Flight deflection measurement system.

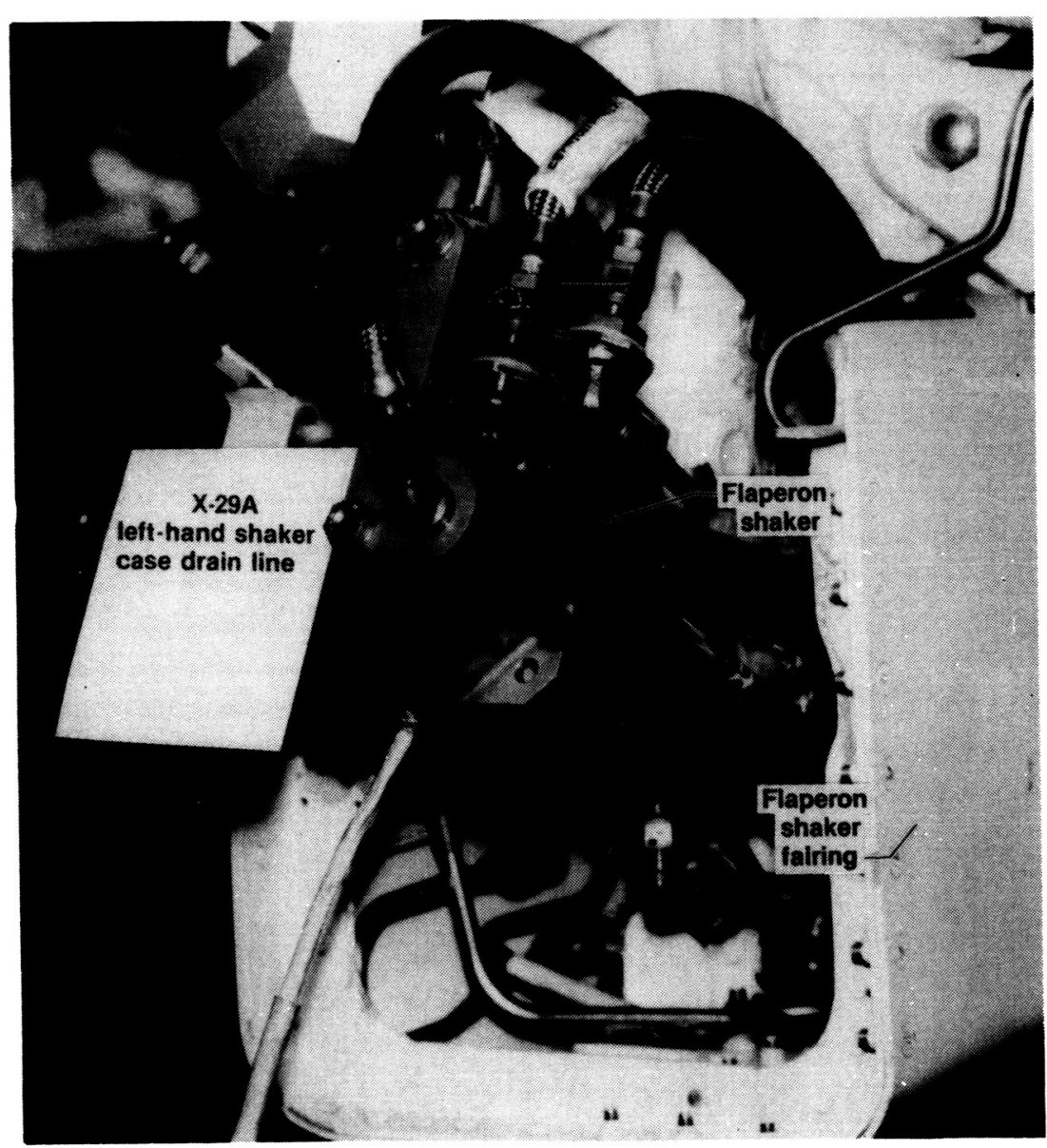

ORIGIML PACE IS OF POOR QUALITY

(b) Flaperon shaker system.

Fig. 3 X-29A special test equipment. 


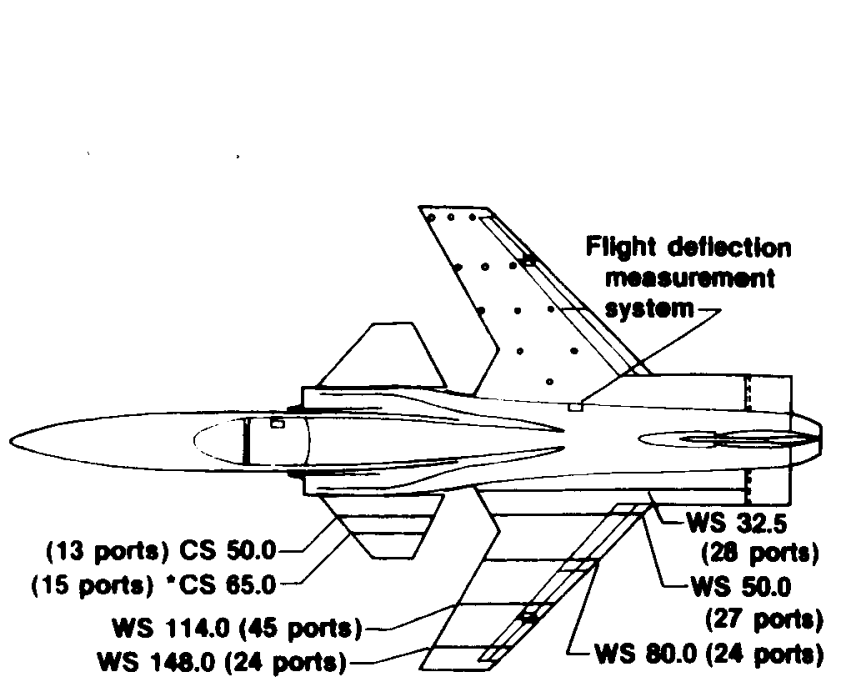

-This row was not on wind tunnel model

(c) Static preseure orifice row location.

Fig. 3 Concluded.

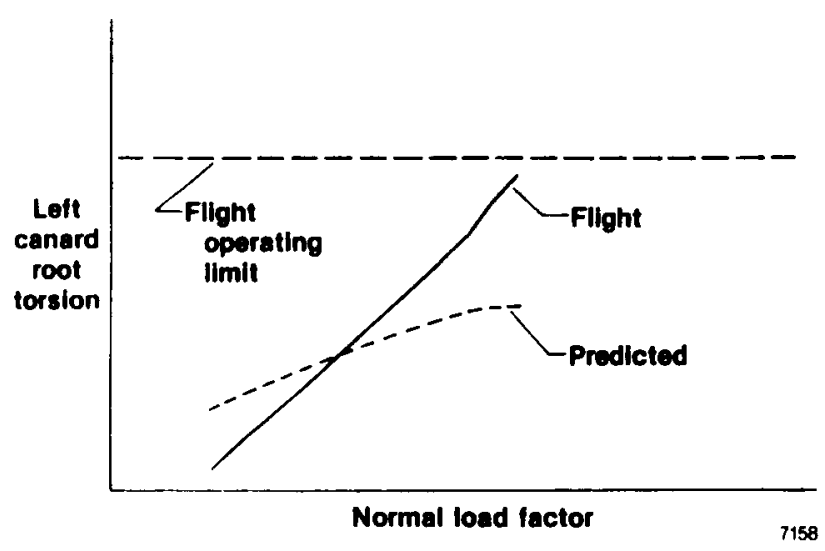

Fig. 5 Canard root torsion load, normal digital mode, $10,000 \mathrm{ft}$ altitude.

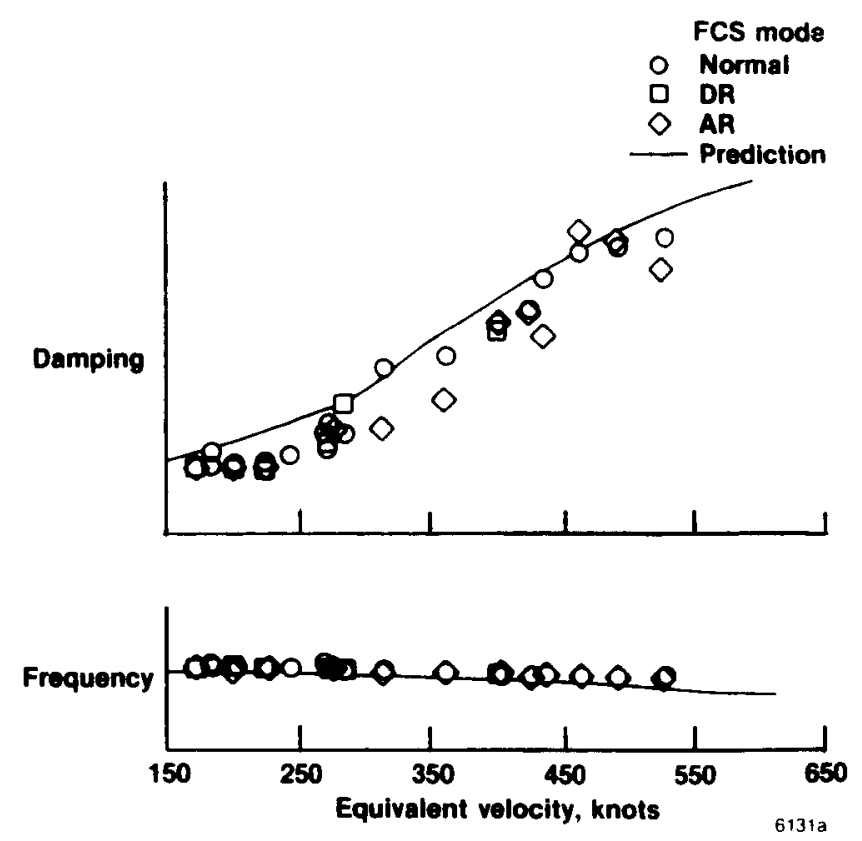

Fig. 4 structural frequency and damping.

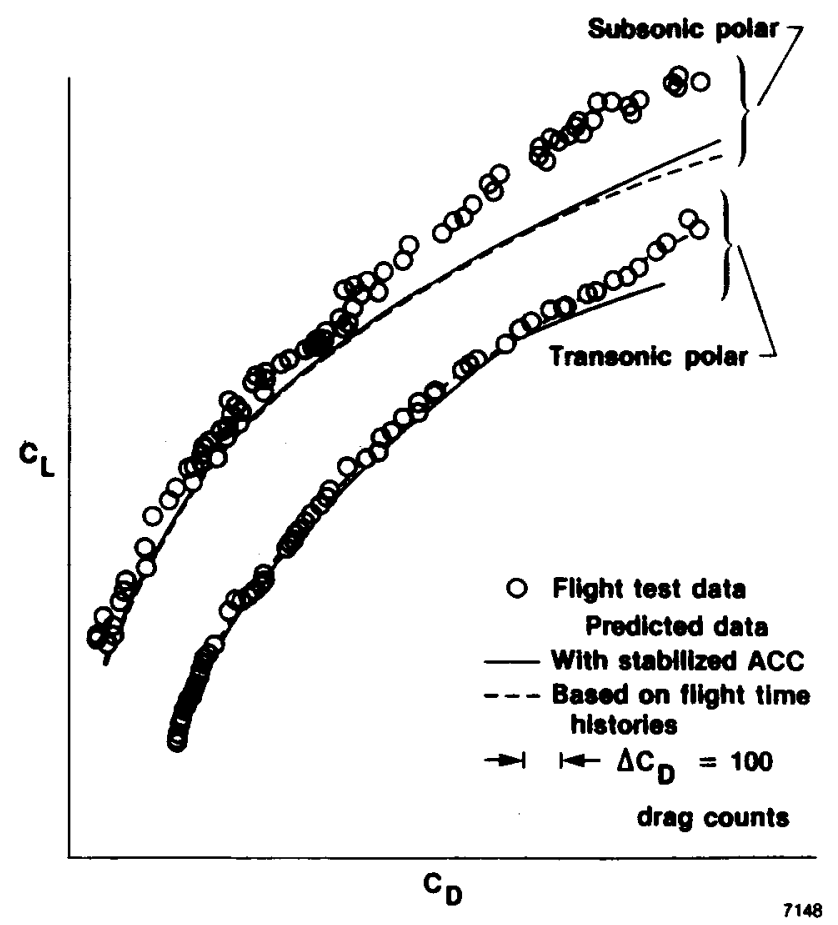

Fig. 6 Subsonic flight drag polare. 

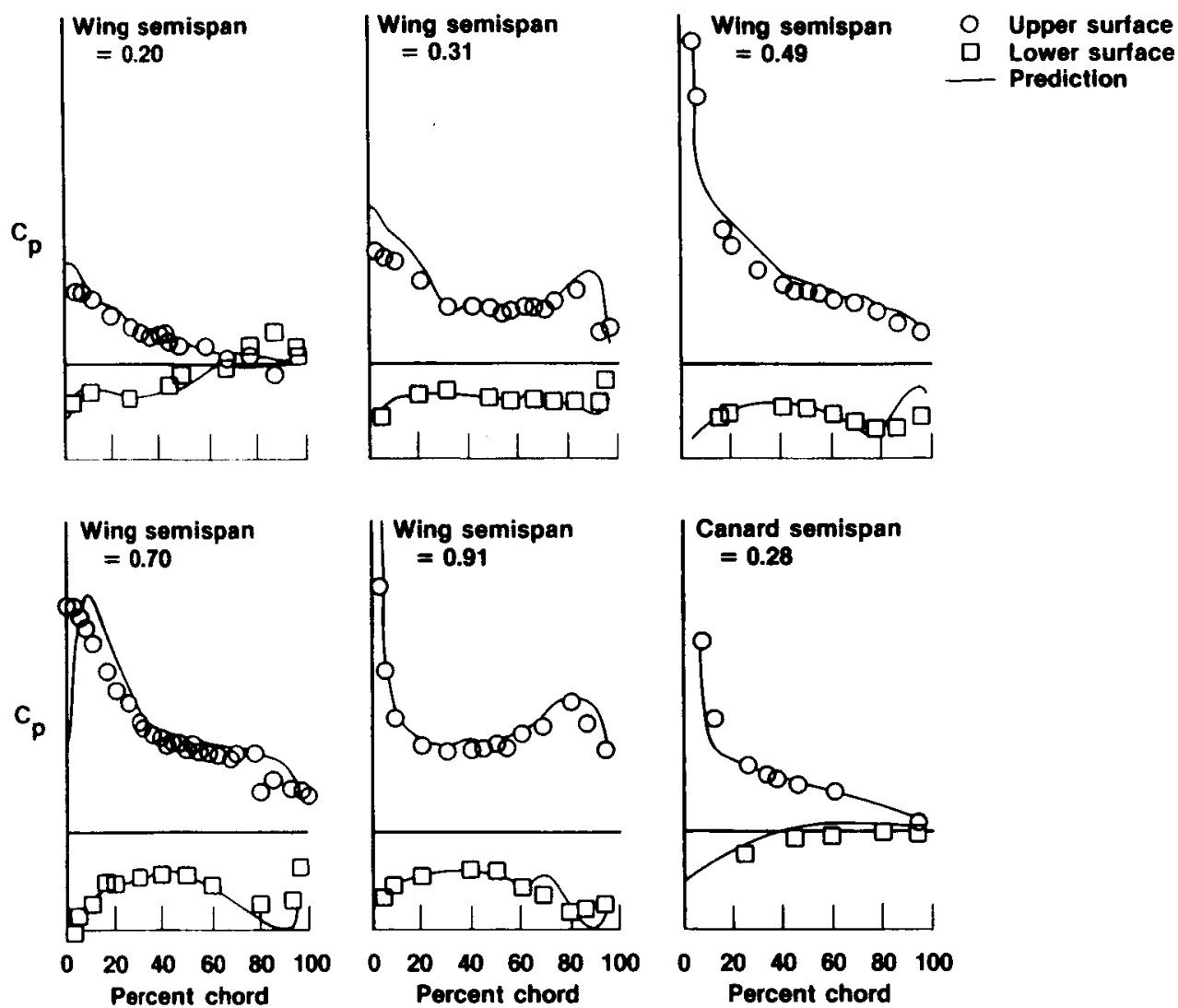

Fig. ? Subsonic wing and canard pressure distribution $\left(C_{p}\right)$.

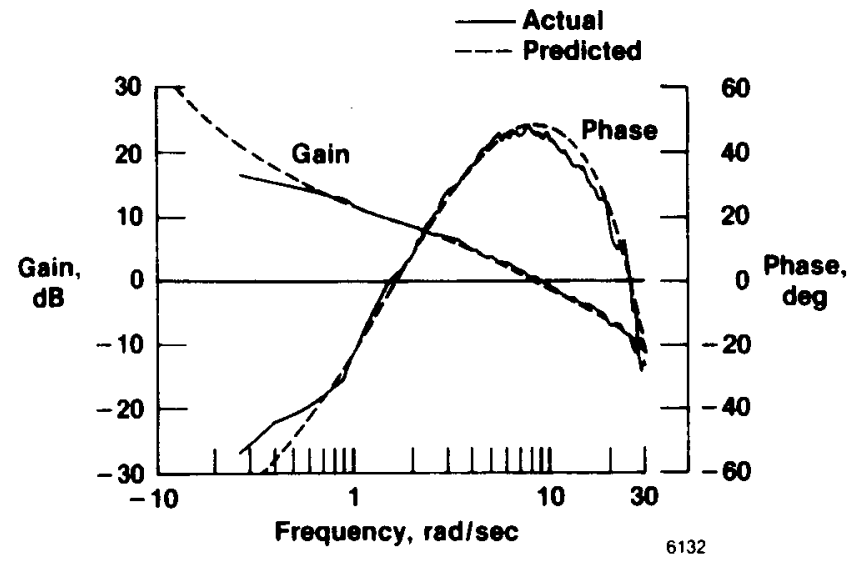

Fig. \& Typioal open-loop frequency respone. 

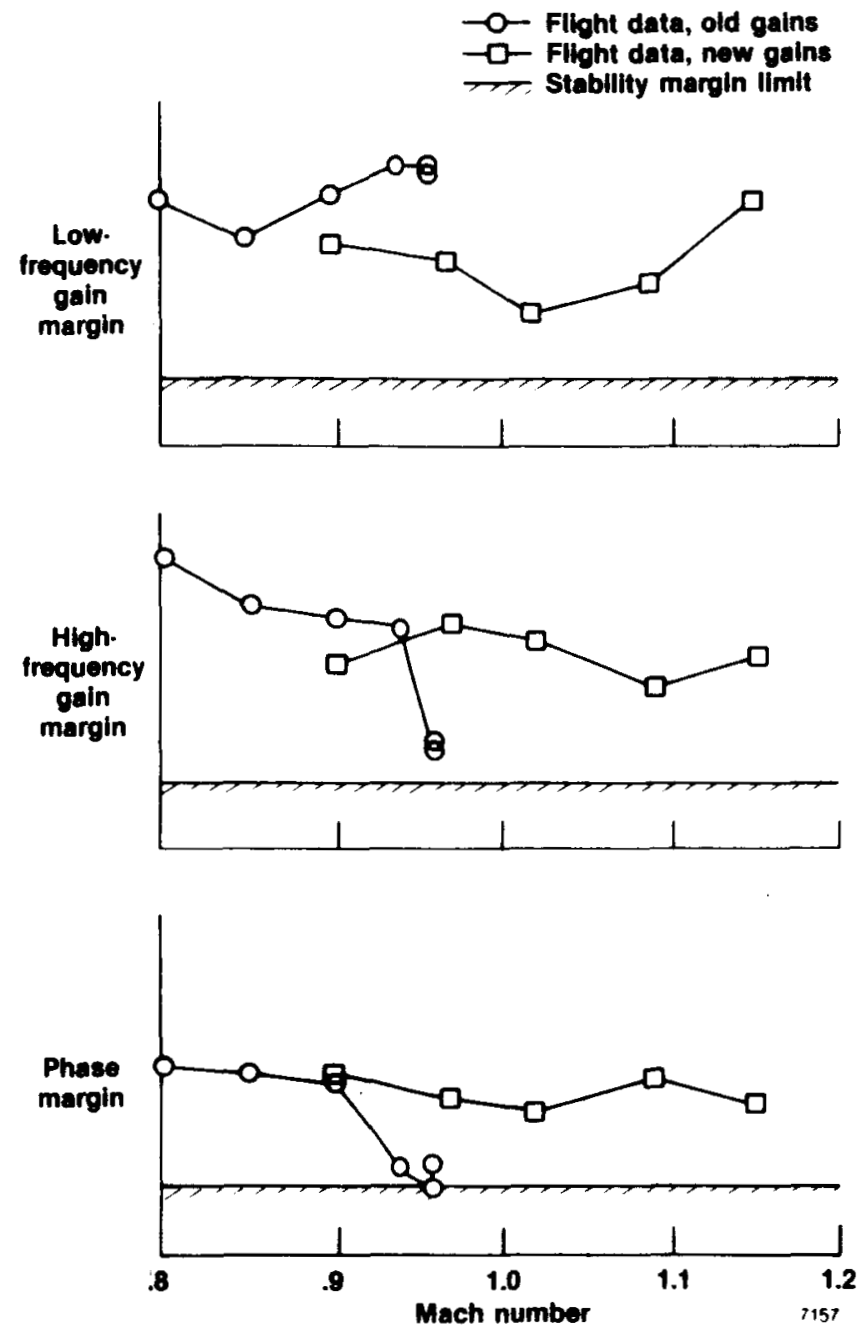

Fig. I Stability margine for nomal digital mode at $15,000 \mathrm{ft}$.

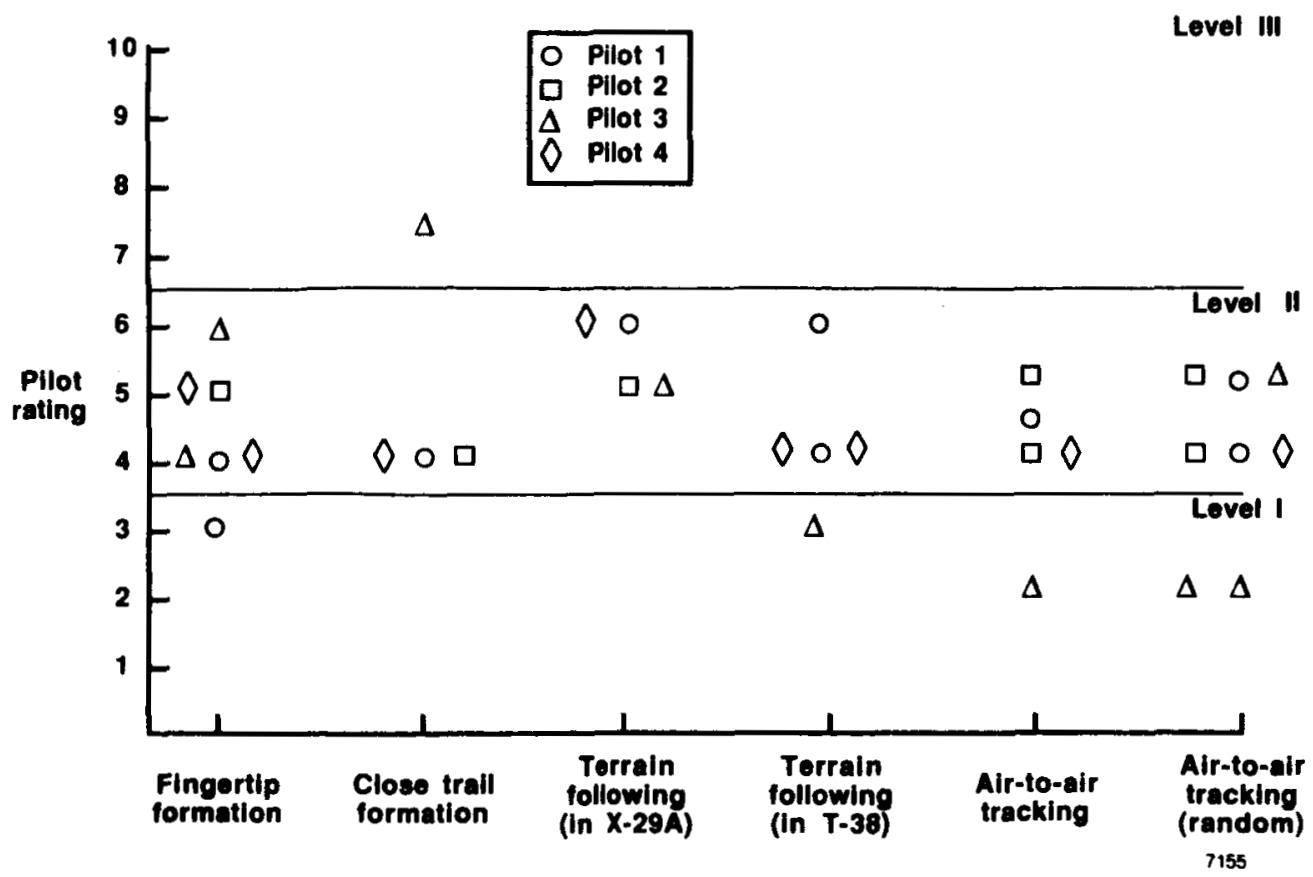

Fig. 10 Pilot Cooper-Harper rating eummary. 


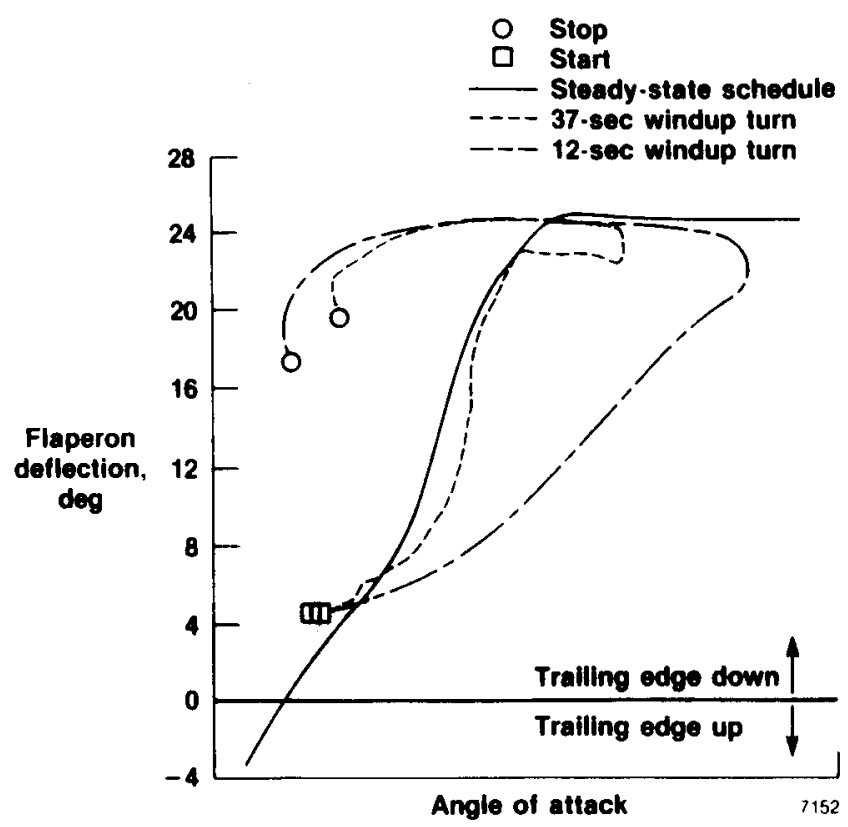

Fig. 11 Longitudinal maneuvering characteristice, normal digital mode.

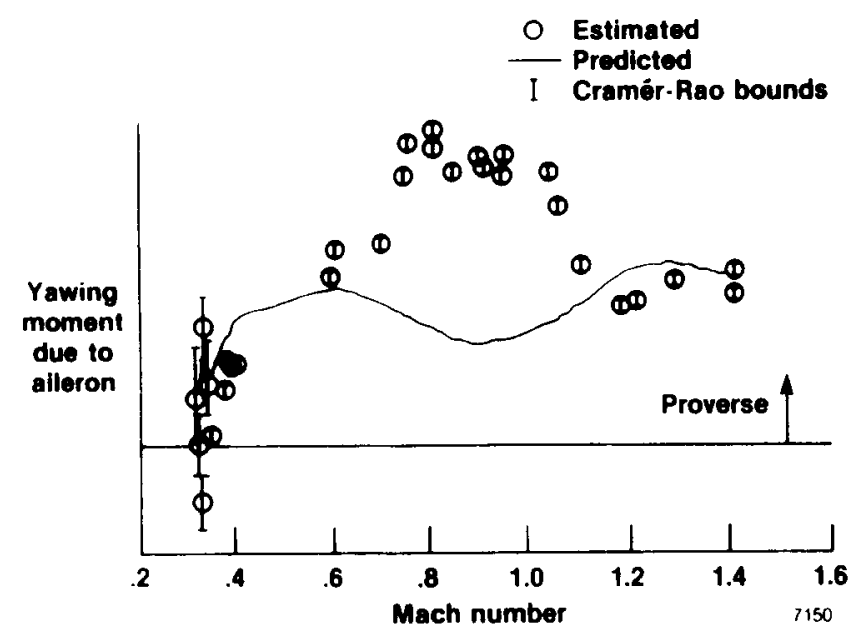

(a) Yawing moment due to aileron.

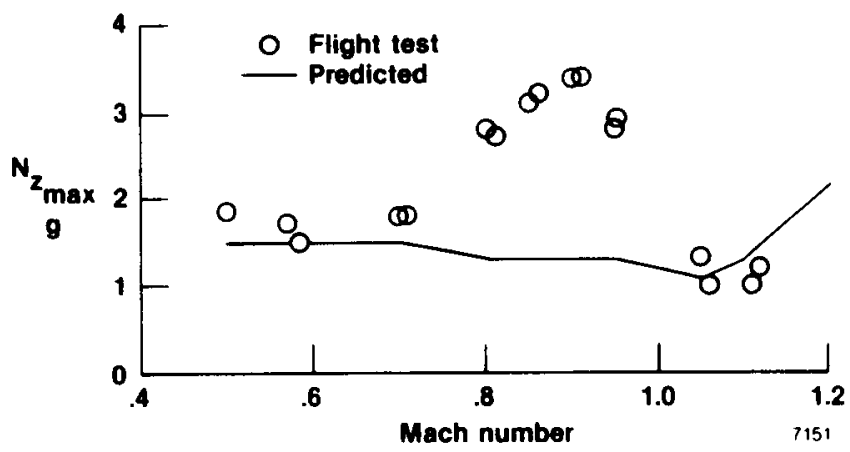

(b) Pitch transients during $360^{\circ}$ rolls.

Fig. 12 Pitch-roll coupling effects.

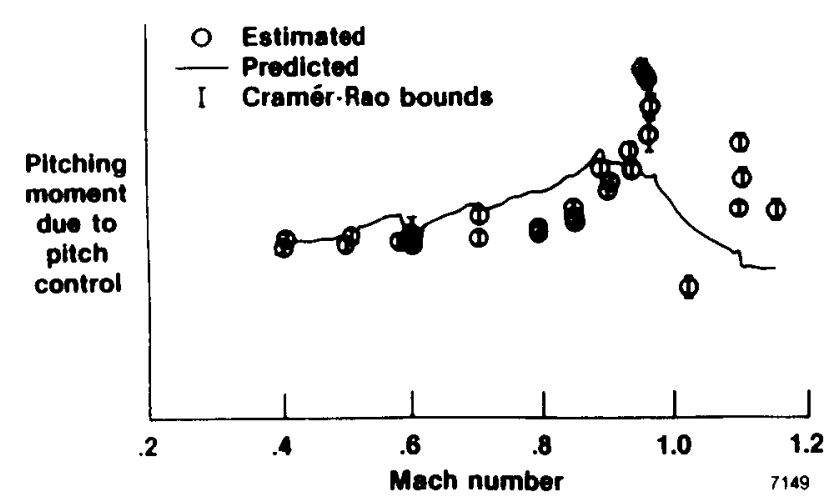

Fig. 13 Pitch control effectiveness.

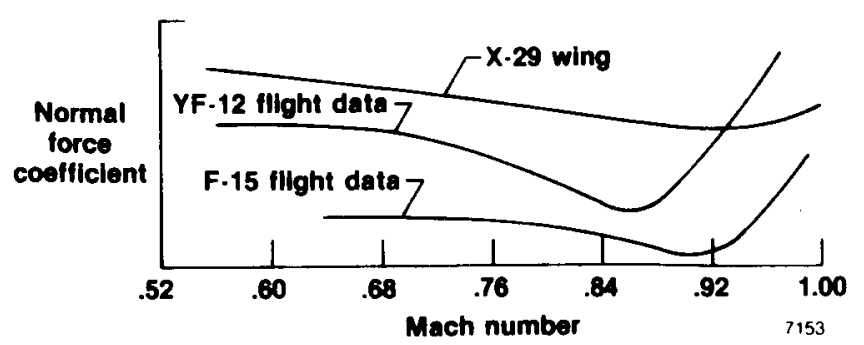

Fig. 14 Buffet intenoity rise (BIR). 


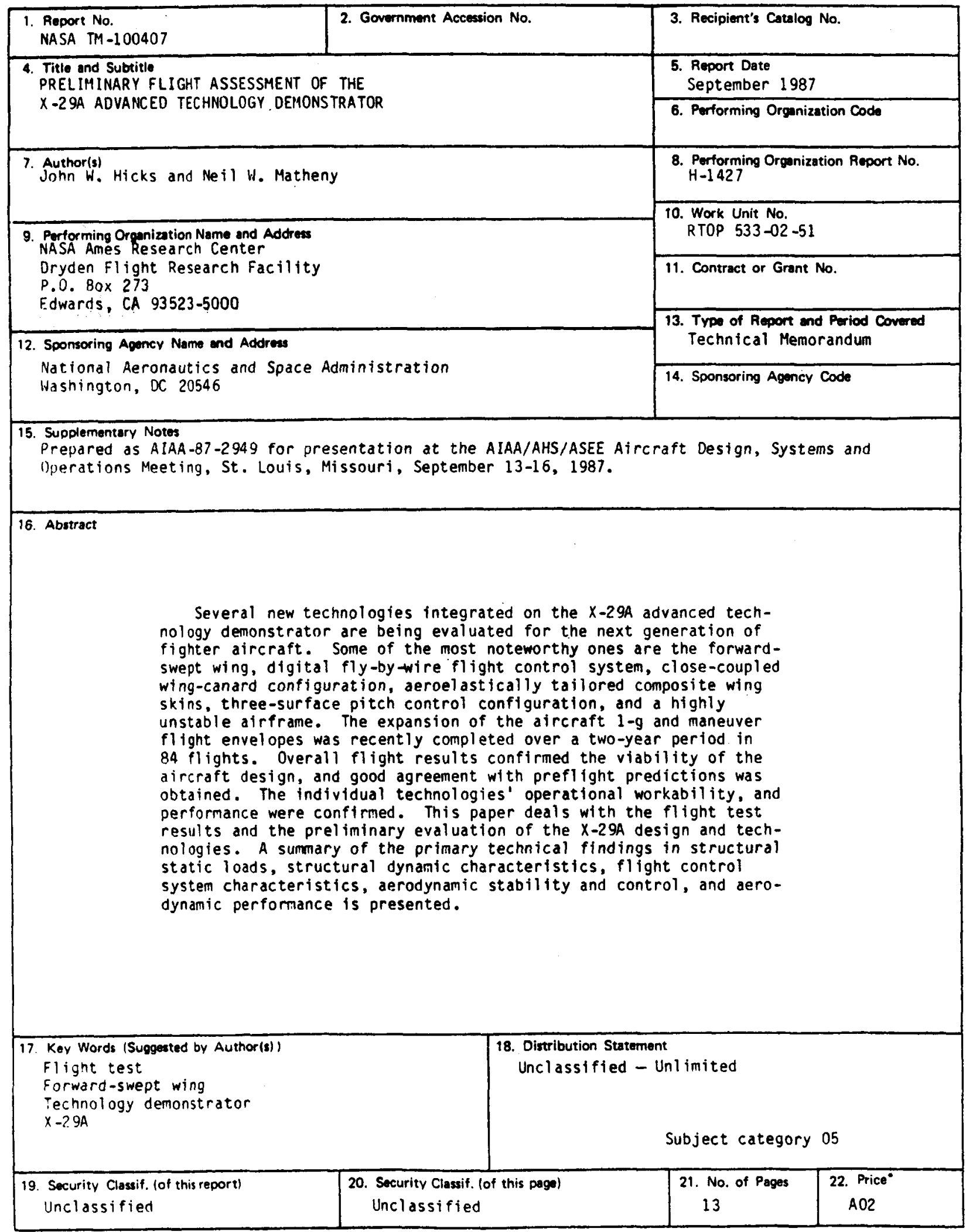

- For sale by the National Techmical Information service, springfield, Virgimia 22161. 